Amaral, A.F.; Oliveira, F.V.; Sousa, T.A. Ecoturismo e acessibilidade: uma trilha em LIBRAS. Revista Brasileira de Ecoturismo, São Paulo, v 15, n.1, fev-abrt 2022, pp. 25-44.

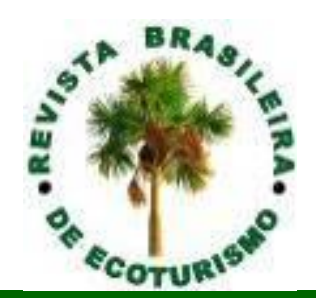

\title{
Ecoturismo e acessibilidade: uma trilha em LIBRAS
}

\section{Ecotourism and accessibility: a trail in LIBRAS}

\author{
Alice Fátima Amaral, Filipe Vieira de Oliveira, Thamyris Alves de Sousa
}

\begin{abstract}
RESUMO: $O$ artigo tem o objetivo de discutir e relatar a experiência de planejar e oferecer uma trilha interpretativa de ecoturismo para um grupo de pessoas surdas, bem como apresentar suas impressões sobre a atividade e a acessibilidade no ecoturismo. Trata-se de uma ação realizada pelo Laboratório de Ecoturismo, do curso de Turismo Patrimonial e Socioambiental, da Universidade Federal do Tocantins, Câmpus de Arraias. A metodologia aplicada teve uma abordagem qualitativa, de caráter descritivo, com trabalho de campo e a aplicação de um questionário para o público participante. Como resultado, observou-se que a comunidade surda muitas vezes deixa de realizar atividades turísticas simplesmente pela falta de comunicação adequada e que a inclusão social dentro do turismo em geral, necessita de melhorias quanto à estrutura física e profissional. As trilhas interpretativas se mostraram, nesse contexto, uma ferramenta interessante para promover a interação do público com o meio ambiente, desde que haja por parte do planejamento dessas atividades, profissionais com domínio da Língua Brasileira de Sinais - LIBRAS, com vistas à garantia do pleno acesso dos surdos às diferentes áreas do lazer e do turismo como direito de todos os cidadãos.
\end{abstract}

PALAVRAS-CHAVE: Ecoturismo; Trilhas Interpretativas; Acessibilidade; Comunidade Surda.

ABSTRACT: The article aims to discuss and report the experience of planning and offering an interpretative trail of ecotourism for a group of deaf people, as well as presenting their impressions about the activity and accessibility in ecotourism. This is an action carried out by the Ecotourism Laboratory, of the Heritage and SocioEnvironmental Tourism course, at the Federal University of Tocantins, Campus de Arraias. The methodology applied had a qualitative approach, with a descriptive character, with field work and the application of a questionnaire to the participating public. As a result, it was observed that the deaf community often fails to carry out tourist activities simply because of the lack of adequate communication and that social inclusion within tourism in general needs improvements in terms of physical and professional structure. In this context, the interpretive trails proved to be an interesting tool to promote the interaction of the public with the environment, provided that, on the part of the planning of these activities, there are professionals with mastery of the Brazilian Sign Language - LIBRAS, with a view to guaranteeing the full access for the deaf to different areas of leisure and tourism as a right of all citizens.

KEYWORDS: Ecotourism; Interpretative Trials; Accessibility; Deaf Community. 


\section{Introdução}

Este trabalho é resultado de uma das atividades realizadas pelo Laboratório de Ecoturismo-LABECOTUR do curso de Turismo Patrimonial e Socioambiental da Universidade Federal do Tocantins, Câmpus de Arraias, e do projeto de pesquisa Cachoeiras e Trilhas com Potencial Turístico nas Serras Gerais/TO: inventariamento e impacto ambiental, e tem o objetivo de discutir e relatar a experiência de planejar e oferecer uma trilha interpretativa de ecoturismo para um grupo de pessoas surdas, bem como apresentar as impressões deste grupo sobre a participação em uma trilha interpretativa e a acessibilidade no ecoturismo.

Para apresentar e discutir os dados coletados, o trabalho utilizou a abordagem qualitativa e pode ser classificado como pesquisa descritiva conforme identificação de Prodanov e Freitas (2013). A coleta de informações foi realizada em trabalho de campo por meio de anotações, fotos das atividades e aplicação de um questionário aos participantes da trilha interpretativa antes e após a atividade. O percurso escolhido para a atividade foi a trilha da Cachoeira da Antiga Usina, localizada na zona rural do no município de Arraias no estado do Tocantins.

Esta proposta decorre do convite feito ao Laboratório de EcoturismoLABECOTUR do curso de Turismo Patrimonial e Socioambiental da UFT em ArraiasTO, para ofertar atividade aos participantes do "II Seminário de Língua de Sinais do Sudeste do Tocantins". Diante do convite surgem os questionamentos "Como receber pessoas surdas em uma trilha interpretativa?", "O turismo atende pessoas com deficiência?".

\section{Referencial teórico}

\section{O turismo e a pessoa com deficiência}

A literatura sobre turismo retrata diferentes conceitos e interfaces a partir da relação dos sujeitos com a cultura e a natureza, podendo ser compreendido como um fenômeno socioespacial complexo que envolve o deslocamento de pessoas por diferentes lugares e distintas motivações, gerando, a partir desta mobilidade, uma forma de interação social, econômica, cultural e ambiental.

Do ponto de vista econômico o turismo é um dos setores da economia que mais gera receitas em todo o mundo, e por este motivo, tornou-se uma esperança de contribuir para o crescimento e desenvolvimento social e econômico dos mais diversos lugares - de uma escala global até as pequenas e localidades. De acordo com Organização Mundial de Turismo (SILVA, 2013), o turismo representa parte significativa dos empregos e do Produto Interno Bruto (PIB) em escala global - um setor produtivo que parecia crescer sem limites. Contudo, foi uma das atividades mais impactadas com a pandemia mundial de covid-19 (SARSCOV-2), que ainda tende a gerar impactos de diversas ordens e possivelmente ressignificar a mobilidade e 0 modo de se fazer turismo no mundo.

Porém, não se deve compreender o turismo apenas como uma atividade econômica, pois isso seria excessivamente genérico como afirma Luchiari (1999), uma vez que há tantas formas de análise quanto possibilidades de compreensão do fenômeno turístico, principalmente sob a ótica de suas manifestações socioespaciais, na medida em que o turismo promove impactos na vida das pessoas e influencia a dinâmica dos lugares por onde se desenvolve, além de proporcionar o encontro, a 
integração e a sociabilização entre diferentes culturas (OLIVEIRA, 2020) sendo ele, portanto, um modelo de representação moderno do modo de ser e existir da sociedade (IRVING, 2015).

Dentre as interfaces mais conhecidas da prática turística está o lazer e os modos de consumo da cultura e da natureza, fatos sociais intrínsecos ao atendimento das necessidades humanas de descanso, prazer e satisfação pessoal. Nestes termos, o tempo livre caracterizado pela sociedade moderna em atividades de lazer se opõe ao tempo de trabalho como um conjunto de atividades exercidas de livre e espontânea vontade com o objetivo de "divertir-se, recrear-se e entreter-se, ou ainda para desenvolver sua informação ou formação desinteressada" (DUMAZEDIER, 1999, p. 34).

O lazer consumido como prática turística dá ao indivíduo a possibilidade de conhecer lugares diferentes do seu habitual, além disso, com o advento das mobilidades e da tecnologia da informação existe uma diversidade de atrativos que podem ser visitados e conhecidos. A prática social do turismo enquanto tempo de lazer, portanto, deu as pessoas à oportunidade de vivenciar momentos diferentes de seu cotidiano - possibilitando descobertas e aprendizagens - sendo o turismo um terreno fértil que promove momentos de troca de experiências entre visitantes e visitados, entre turistas e comunidades receptoras.

Não obstante, o turismo promove impactos devido às próprias assimetrias existentes na sociedade, sendo caracterizado por sua complexidade e natureza multifacetada. Nesse sentido, alguns aspectos do turismo como objeto e produto do lazer moderno têm demonstrado que o acesso a ele também reflete as desigualdades existentes na sociedade. Um exemplo desse acesso desigual é a inclusão de determinados grupos sociais, pois assim como qualquer produto ou serviço disponível para o consumo, o turismo também é uma atividade de distinção social, parte integrante de uma indústria cultural massificada que transformou formas de sociabilidade e o direito social do lazer em mercadoria.

Um problema que torna o direito ao lazer e ao turismo ainda mais desigual, reside no fato de apesar das várias formas de mobilidade proporcionadas pelo turismo, o acesso a determinados lugares é restrito a certos públicos, essencialmente no que se refere ao acesso a lugares e ao consumo turístico por pessoas com deficiência $(P c D)$.

Mendes e Paula (2008), destacam que o turismo deve ser analisado diante de seu aspecto social que garante a aceitação e a valorização da igualdade humana assumindo o seu papel perante as mais diversas atitudes sociais. Deste modo, o lazer e o turismo como direitos sociais devem promover a inclusão social, e, com isso, deve ser planejado e organizado para atender a todos, incluindo às pessoas com deficiência e demais pessoas com necessidades específicas.

Muitas vezes as pessoas com deficiência ou com necessidades específicas são vistas como pessoas doentes que não possuem a capacidade de realizar certas atividades (MENDES; PAULA, 2008). No entanto, considerar as motivações desses sujeitos é um passo importante no processo de construção de uma sociedade mais inclusiva. E apesar da amplitude das muitas publicações existentes na área de turismo e afins, são poucas as que abarcam estudos sobre o turismo e a pessoa com deficiência (MENDES; PAULA, 2008). 
O Código Mundial de Ética do Turismo (BRASIL, 2019) enfatiza que o desenvolvimento do turismo responsável, acessível e sustentável também é direito de todos. No Brasil, o decreto 3.298 de 1999 garante a o pleno direito da pessoa com deficiência seus direitos básicos que devem ser assegurados pelo Estado, que incluem, em vista disso, o direito ao lazer e ao turismo, como segue:

Art. 2 Cabe aos órgãos e às entidades do Poder Público assegurar à pessoa portadora de deficiência o pleno exercício de seus direitos básicos, inclusive dos direitos à educação, à saúde, ao trabalho, ao desporto, ao turismo, ao lazer, à previdência social, à assistência social, ao transporte, à edificação pública, à habitação, à cultura, ao amparo à infância e à maternidade, e de outros que, decorrentes da Constituição e das leis, propiciem seu bem-estar pessoal, social e econômico (BRASIL, 1999).

A década de 1980 foi um marco na criação de leis e decretos voltados para inclusão de pessoas deficientes no Brasil, porém, quando se trata do turismo e a inclusão dessas pessoas ainda há pouca evolução, principalmente na implementação de lugares com estrutura para atender este público, que no Brasil pode chegar a 45 milhões de pessoas segundo o último censo do IBGE (2010).

De acordo com Costa (2012), os ambientes naturais, culturais e sociais disponíveis para o turismo devem ser bem planejados e ter boa infraestrutura para receber pessoas com ou sem necessidades especificas. Essas adaptações vão permitir que toda comunidade usufrua da atividade turística em seus momentos de descanso, lazer e turismo.

A contribuição do turismo é possibilitar que as pessoas com deficiência conheçam suas capacidades e desenvolvam suas habilidades de maneira prazerosa, em contato com ambientes diversos e pessoas fora do seu círculo habitual; é ajudá-la a compreender melhor aquilo que deseja e necessita, com vistas a um aumento na qualidade de vida e maior participação como cidadã; em suma, é fazer com que ela migre do papel de coadjuvante para o de protagonista (MENDES; PAULA, 2008, p. 335).

A acessibilidade dos lugares, atrativos e demais serviços juntamente com o planejamento turístico se torna uma ferramenta necessária para que a inclusão das pessoas com deficiência aconteça. Assim, quebrando barreiras e promovendo a qualidade de vida de todas as pessoas no pleno exercício da cidadania.

Não se devem separar as pessoas com deficiência dos outros turistas durante o exercício da atividade. Para o turismo representar uma parte do desenvolvimento e bem-estar integral das pessoas com deficiência, ele precisa ser realizado no mesmo espaço em que convivem as pessoas sem deficiência. Se o espaço é o mesmo, temos que garantir a acessibilidade. Possibilitando o convívio entre os diversos segmentos da sociedade e a pessoa com necessidade especial, desenvolvendo maior interação (MENDES; PAULA, 2008, p. 330-331). 
De modo geral é percebido que a prática social do turismo, especialmente no Brasil, demonstra problemas na acessibilidade das instalações e no atendimento hospitaleiro das pessoas com deficiência ou necessidades específicas. Sendo assim, é importante e necessário qualificar a estrutura física e profissional envolvidas na atividade turística para os conceitos, normas e legislação referente a inclusão e a acessibilidade seja plenamente satisfatória. A acessibilidade no turismo é um fator que deve estar presente nos projetos turísticos comerciais, bem como o setor do turismo deve qualificar profissionais para garantir um atendimento de qualidade e inclusivo a todos os públicos.

Os serviços, os profissionais e a sociedade em geral não estão aptas a recepcioná-los. Contudo, chama-se a atenção ao fato de que isso já deveria estar superado e implementado conforme o que preconiza a Lei 13.146 de 2015:

\begin{abstract}
Art. 42. A pessoa com deficiência tem direito à cultura, ao esporte, ao turismo e ao lazer em igualdade de oportunidades com as demais pessoas, sendo-Ihe garantido o acesso: I - a bens culturais em formato acessível; II - a programas de televisão, cinema, teatro e outras atividades culturais e desportivas em formato acessível; e III - a monumentos e locais de importância cultural e a espaços que ofereçam serviços ou eventos culturais e esportivos (BRASIL, 2015, p. 10).
\end{abstract}

Com isso, percebe-se a urgente necessidade de acessibilidade em todas as áreas com vistas a inclusão social da pessoa com deficiência. $E$ isso não pode ser diferente no turismo. Em vista dessa necessidade, neste trabalho, voltamos o olhar para a prática do turismo pela pessoa surda, especificamente para a experiência dos turistas surdos na prática do chamado ecoturismo.

\title{
O turismo e a pessoa surda
}

Atividades turísticas com as adequações que garantam a acessibilidade da pessoa com necessidades específicas constituem-se não somente em uma oportunidade de mercado e potencial econômico, mas um evidente processo de inclusão social e do direito ao lazer (LIMA, 2004; ANDRADE; ALVES, 2011) e o abarcamento da pessoa surda na atividade turística é um exemplo dessa oportunidade.

Andrade e Alves (2011), afirmam que a pessoa surda possui os mesmos interesses de todas as pessoas, são cidadão que têm trabalho, gozam de férias, têm interesse em praticar esportes e fazer turismo, ou seja, a surdez é uma deficiência sensorial e possibilita ao surdo total mobilidade, e assim, o indivíduo está apto a executar qualquer atividade em qualquer um dos segmentos oferecidos pelo turismo.

No entanto, sendo o lazer proporcionado pelo turismo um elemento que implica no consumo cultural, a comunicação torna-se muito importante. Realizar uma boa comunicação, nesse sentido, significa saber se comunicar com todos, o que incluem as pessoas surdas, e essa comunicação deveria ser de responsabilidade dos lugares e dos atrativos, e não do turista. Acertar na comunicação resulta numa experiência satisfatória, avaliação positiva, divulgação e retorno aos lugares turísticos. Além de 
ser um estímulo para maior disposição em realizar outras atividades turísticas (ANDRADE; ALVES, 2011).

Tem-se, portanto, a comunicação como um dos agravantes na acessibilidade ao turismo para a pessoa surda. Andrade e Alves (2011) enfatizam a importância da criação de novas estratégias para atendimento da pessoa surda, resultando também em benefício a atividade turística, garantindo, por fim, a igualdade na sociedade e no acesso ao lazer. A inclusão de intérpretes com conhecimento em Língua Brasileira de Sinais - LIBRAS, por exemplo, representa uma das possíveis estratégias.

A LIBRAS (segunda língua oficial do Brasil) possibilita à pessoa surda no geral, desenvolver a sua comunicação, e no caso do turismo, implica na possibilidade de conhecer novas culturas e valorizá-las, conhecer as histórias e a origem de cada local visitado e usufruir completamente dos atrativos turísticos, assim como o ouvinte, que necessita ouvir para apreciar, compreender e ter uma experiência satisfatória com o lugar visitado.

Para criar um vínculo entre a pessoa surda e a atividade turística, portanto, é importante ampliar o conhecimento em LIBRAS dos atores sociais atuantes no turismo. Nesse sentido, cabe aos estabelecimentos contratar profissionais que proporcionem serviços de tradução e interpretação para este público (ANDRADE e ALVES, 2011). A inclusão e melhoria no atendimento também pode ser obtido a partir da contratação de funcionários surdos. Essa ação além de inclusiva pode ser um diferencial para que pessoas surdas optem por um determinado atrativo turístico, além de incluir a pessoa surda no mercado de trabalho do turismo (LIMA, 2004).

Mas infelizmente são poucos registros encontrados sobre locais no Brasil que agregam a seus serviços a algum tipo de atuação inclusiva, seja pela contratação, estruturação ou capacitação de funcionários, bem como a atividades direcionadas à pessoa surda. Alguns exemplos encontrados são:

Projeto Guia e Monitores do Carnaval - BA: contratou intérpretes de LIBRAS para postos de informações no aeroporto Luís Eduardo Magalhães e na Rodoviária da capital, Salvador (ANDRADE; ALVES, 2011).

Giulia - Mãos que falam - AM: No Bosque da Ciência do Instituto Nacional de Pesquisas da Amazônia - Inpa/MCTIC (SHIMOSAKAI, 2019).

Festividade de São João de Caruaru - PE: Na busca por mais turistas, a prefeitura de Caruaru contrata e disponibiliza intérprete de LIBRAS que atendem aos visitantes surdos. Essa ação tem aumentado o número de pessoas surdas que escolhem participar da festa (FLORÊNCIO, 2016).

Planejamento Setorial do Turismo em Juiz de Fora - MG: Em 1997 a Prefeitura Municipal criou o Planejamento Setorial do Turismo de Juiz de Fora, com o objetivo de promover o desenvolvimento e o crescimento do município, assim profissionalizando as equipes técnicas e executivos, para desenvolver a comunicação e a participação dos envolvidos. (LAGES; MARTINS, 2006).

Projetos turísticos voltados ao atendimento da pessoa surda não são fáceis de serem encontrados e muitos são encerrados junto com o período de gestão do proponente. Adequação da atividade turística em áreas naturais não foram identificados na literatura, com exceção do "Giulia - mãos que falam" e que tem a proposta de se tornar permanente para os visitantes. No Brasil, a demanda por melhoras na estrutura física e de atendimento da pessoa surda, bem como de outras 
deficiências é uma realidade e precisa ser modificada para promover e efetivar a inclusão social, e no caso do lazer e do turismo, melhorar a experiência de visitação e comunicação dos ouvintes com a comunidade surda.

\section{Trilhas interpretativas}

No que diz respeito ao ecoturismo, das atividades prezam pela boa comunicação entre o lugar e os visitantes são as trilhas interpretativas. Essas atividades podem ser consideradas instrumentos para formação de um cidadão com maior consciência ambiental. A experiência proporcionada em ambiente natural pode desencadear no sujeito a necessidade de repensar suas ações e atitudes, dessa forma, adquirindo hábitos importantes para conservação da natureza e melhoria da qualidade de vida (EISENLOHR et al., 2013).

As trilhas interpretativas também podem ser consideradas um meio de educação ambiental, como um ato de transmitir a conscientização preservacionista, para promover a conscientização sobre a exploração e o consumo intenso dos recursos naturais. Diante disso, nota-se diversos meios de desenvolver trilhas interpretativas, pois é um meio de transmitir o contato direto com a natureza, fazendo com que o participante tenha uma conexão com o meio natural (LIMA; SILVA, 2020).

Segundo Lima e Silva (2020) as trilhas interpretativas são ações construídas que facilitam o desenvolvimento da educação, fazendo com que o ser humano reflita sobre as consequências dos atos cometidos diante de seu comportamento e atitudes. A cada reflexão alcançada o indivíduo muda sua forma de pensar, ou seja, sua linha de pensamento não será mais a mesma, assim colaborando para tomada de consciência e preservação do meio ambiente. Trata-se de uma forma criativa de promoção do contato do visitante com a natureza, por meio de atividades ecológicas e de educação ambiental. Essas atividades incentivam o visitante a fazer uma reflexão mais críticas sobre as questões ambientais.

As trilhas interpretativas e a educação ambiental são abordagens constituídas por grandes valores e atitudes, onde oferecem não somente informações como também experiências que possibilitam uma construção de um vínculo entre o ser humano e natureza. A interpretação ambiental tanto em ambientes naturais quanto em ambientes artificiais é fundamental para 0 desenvolvimento das trilhas Interpretativas e da consciência ambiental.

As trilhas interpretativas não existem somente para a comunicação de fatos, datas e conceitos, mas também para compartilhar experiências que levem os visitantes, sejam alunos, professores ou turistas a apreciar, a entender, a sensibilizar, a cooperar na conservação de um recurso natural e a educar. (SANTOS; FLORES; ZAZIN, 2011, p. 2-3).

Para os autores Santos, Flores e Zazin (2011), a trila interpretativa promove atividades praticadas ao ar livre que facilitam a interação do ser humano com o meio natural. Esses espaços associados as atividades, normalmente criam um clima agradável e gratificante para a construção de novos conhecimentos. O que colabora para eliminar barreiras, superar limites e promover inclusão. Os autores também ressaltam que as trilhas interpretativas poderiam ser incluídas no processo 
educacional das escolas, por apresentar características que podem auxiliar no aprendizado de conceitos e formação de um cidadão mais crítico sobre questões ambientais e relação com a sociedade.

\section{Materiais e métodos}

\section{Sujeitos participantes da pesquisa e procedimentos metodológicos aplicados}

A pesquisa foi realizada durante o "Il Seminário de Língua Brasileira de Sinais do Sudeste do Tocantins", evento acadêmico que ocorreu na Universidade Federal do Tocantins, Câmpus Arraias, nos dias 30 e 31 de agosto de 2019 e contou com aproximadamente 115 participantes, sendo 23 pessoas surdas e 1 pessoa surdacega. Durante o evento, todas as pessoas foram convidadas a participar de uma trilha interpretativa promovida pelo LABECOTUR das quais 14 aceitaram o convite.

Apesar da existência de pessoas surdas na cidade, a comunidade ainda não está organizada, isto demonstra uma ausência de políticas inclusivas, na medida em que se verifica que esta comunidade, em sua maioria, não sabe utilizar a LIBRAS, sendo muito difícil o desenvolvimento da comunicação, bem como a aproximação da universidade e das atividades acadêmicas com este público. Deste modo, o evento proporcionou a oportunidade de contato com pessoas surdas, facilitando a coleta de informações necessárias para realização deste trabalho, com o auxílio e mediação de alguns professores e intérpretes de LIBRAS voluntários.

A trilha ocorreu em Arraias, município localizado no Sudeste do estado do Tocantins na divisa com o estado de Goiás, uma cidade pequena em meio as colinas das Serras Gerais numa paisagem única do cerrado tocantinense. De acordo com Santos, Amaral e Messias (2020), o município dispõe de um potencial natural constituído por grutas, rios, montanhas e expressões culturais que rementem às comunidades tradicionais quilombolas ali presentes, além de festas e demais manifestações tradicionais e religiosas, conferindo a região um importante patrimônio cultural e natural.

Pesquisa realizada por Santos, Amaral e Messias (2020) identificou pontos com potencial turístico no rio Arraias, onde muitos destes pontos já são usados pela população local como áreas de lazer. Um desses locais é conhecido como Cachoeira da Antiga Usina, localizada numa propriedade particular na zona rural, mas muito próxima a área urbana de Arraias. O acesso a esse ponto pode ser feito por caminhada através de trilha marcada pelo pisoteio do gado (SANTOS; AMARAL; MESSIAS, 2020). Este foi o local escolhido para a realização da atividade com os participantes.

Num primeiro momento, antes do início da trilha, foi aplicado um questionário que buscou identificar o perfil dos participantes e suas percepções relacionadas à prática do turismo e acessibilidade para a comunidade surda. $\mathrm{E}$ após o retorno da trilha foram feitas perguntas abertas para obter a percepção do participante sobre a trilha interpretativa oferecida e os aspectos relacionados a acessibilidade e a condução da atividade para o público surdo.

Antes da aplicação o questionário foi submetido a um professor e a alguns alunos surdos a fim de realizarem uma análise crítica averiguando se a forma de escrita (português) das perguntas estava acessível para o entendimento da pessoa surda, e a partir das observações deles, algumas perguntas foram reformuladas. 
Alguns alunos e um professor surdo também auxiliaram como intérpretes na aplicação do questionário, bem como no desenvolvimento da trilha interpretativa.

A trilha percorrida por caminhada de nível leve para médio tem cerca de 2,5 $\mathrm{km}$, onde $80 \%$ do percurso é feito em trecho de descida até chegar à cachoeira. $A$ trilha passa por três propriedades particulares, que autorizaram a realização da caminhada. No percurso, além de observar impactos decorrentes da atividade humana, foi possível contato com espécies vegetais e animais remanescentes do Cerrado Brasileiro. Outra característica favorável da trilha é a beleza da paisagem devido ao relevo montanhoso característico do Cerrado local.

A estratégia de interpretação foi a caminhada guiada, com presença de condutor ouvinte e intérprete de LIBRAS. No percurso, foram estabelecidos pontos de parada para interação e observação da paisagem e seus componentes. A proposta da trilha tinha como objetivo desenvolver no participante um novo olhar sobre o Bioma Cerrado, sua importância e a relação com o ser humano. Temática que pode ser ofertada a qualquer público, cuja diferença, neste caso, foi a mediação de um intérprete de LIBRAS.

Assim, o percurso da trilha foi divido nos seguintes pontos:

\section{1ํ Ponto: Instrução sobre a trilha e primeira dinâmica interpretativa}

Os participantes se dirigiram ao Laboratório de Ecoturismo-LABECOTUR do curso de Turismo Patrimonial e Socioambiental da UFT (Figura 1) onde foram recebidos por um grupo composto por três intérpretes voluntários, um estagiário voluntário do LABECOTUR, um voluntário com vínculo familiar ao proprietário da fazenda onde se encontra a cachoeira e a coordenadora do laboratório.

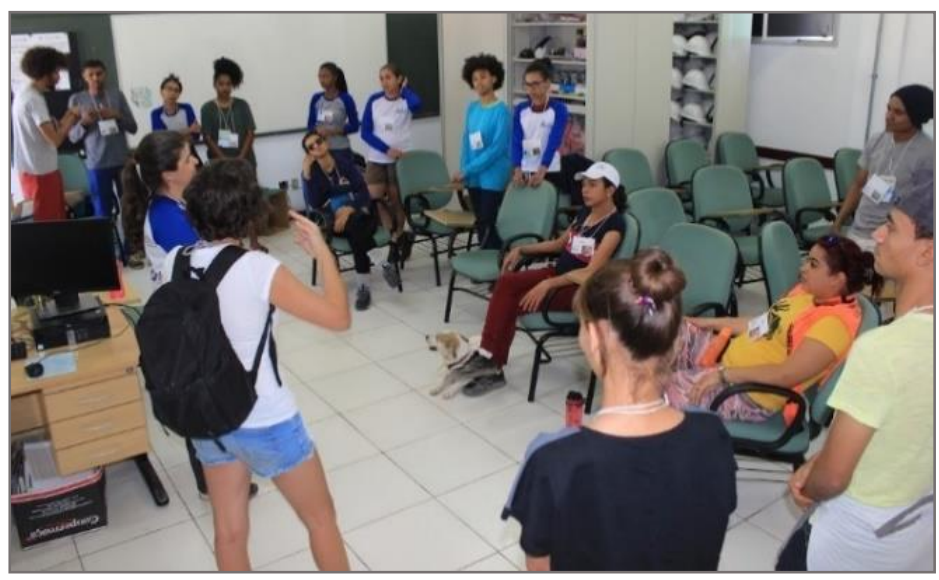

Figura 1: Orientações repassadas aos participantes

Figure 1: Ecotourism and accessibility: a trail in LIBRAS.

Fonte: Arquivo dos autores, 2019.

Source: Authors' archive, 2019

Em seguida foi apresentado o tema da trilha, características da trilha (dificuldade, tempo de duração, extensão etc.), orientações sobre comportamentos de segurança durante o percurso e o que poderia ser observado no caminho. Também foram emprestados material e vestimenta adequada para fazer a trilha, como 
perneiras, cantis com água, chapéu e outros equipamentos de proteção disponíveis no Laboratório de Ecoturismo.

Ao final da orientação cada participante recebeu um crachá contendo uma figura. Cada participante passou a ter sua identidade referente a essa figura do crachá que poderia ser um representante da fauna ou flora do Cerrado brasileiro. Também foi explicado aos participantes que, se prestassem atenção, possivelmente encontrariam os verdadeiros representantes das figuras no decorrer da trilha.

A fim de estimular a colaboração em grupo e assegurar maior cuidado com possíveis acidentes, todos aceitaram participar da brincadeira "dinâmica do anjo" Assim, as mesmas figuras dos crachás foram colocadas em um envelope. Cada participante retirou uma e guardou. Ao pegar a figura, o participante (anjo) assume a reponsabilidade de colaborar e cuidar da pessoa cujo crachá tenha a mesma figura sorteada, sem deixar que a pessoa perceba. Esse cuidador é chamado de anjo, pois na cultura popular religiosa o anjo cuida de "você, mas você não o vê".

Ao final da trilha, retornando ao laboratório, os anjos indicaram quais as dificuldades que tiveram que resolver para ajudar seus protegidos, e no fim do relato as pessoas tinham que adivinhar sobre quem o anjo estava se referindo. Finalizando com a discussão sobre a importância do comportamento individual e da colaboração coletiva durante um percurso de ecoturismo para o bem comum e proteção do meio ambiente.

\section{2ํ Ponto: homem como agente transformador da paisagem natural}

O início da trilha começou na área urbana da cidade, onde pôde ser observado a presença de lotes baldios. Mas logo é possível observar o início da mudança de paisagem urbana para áreas mais rurais identificando o quanto a atividade humana pode modificar o ambiente e promover, como consequência a degradação do bioma.

Ao interagir/interferir na natureza o homem obtém recursos indispensáveis a sua sobrevivência e perpetuação na sociedade, porém, deve-se considerar que nem sempre essa interferência respeita o fato de que os recursos naturais, utilizados, são esgotáveis e precisam ser utilizados de forma planejada e sustentável. Os Biomas brasileiros são bons exemplos dessa interferência. As áreas naturais estão cada vez mais reduzidas, colocando em risco biodiversidade e recursos naturais essenciais à vida, como por exemplo os recursos hídricos.

\section{3ํ Ponto: O Bioma Cerrado}

O espaço escolhido fica no final do primeiro trecho de descida, uma parte plana da trilha, formando um mirante de onde é possível ver o relevo montanhoso do entorno a cidade, o vale do Rio Arraias, uma barragem abandonada e a vegetação remanescente do chamado Cerrado típico, passando para uma vegetação mais adensada e mais alta (Figura 2). Nesse espaço foi possível discutir características ecológicas do Bioma Cerrado os impactos e redução da sua área nativa. 


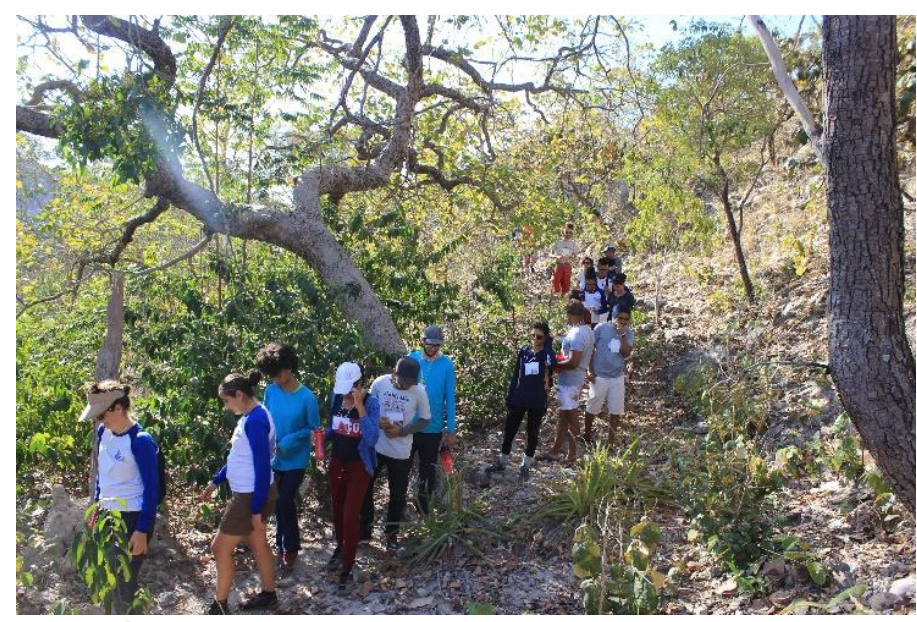

Figura 2: Momento de mudança na vegetação.

Figure 2: Moment of change in vegetation Fonte: Arquivo dos autores, 2019. Source: Authors' archive, 2019.

O Bioma Cerrado é considerado a savana mais rica em biodiversidade do mundo e detém cerca de um terço da diversidade do país. Além disso, as três maiores bacias hidrográficas da América do Sul (Tocantins-Araguaia, São Francisco e Prata) têm suas nascentes protegidas pelo Cerrado o que favorece sua biodiversidade (RIBEIRO; WALTER, 2008). Sua paisagem é composta por um complexo de fitofisionomias que inclui formações florestais em meio a formações savânicas e campestres com alta biodiversidade. Sendo possível observar onze tipos de fitofisionomias no Cerrado (RIBEIRO; WALTER, 2008).

A diversidade de fitofisionomias no Cerrado resulta e e distribuição das espécies vegetais no Cerrado é afetada por fatores como clima, disponibilidade de água, geomorfologia, topografia, latitude, fertilidade e profundidade do solo, frequência e intensidade de fogo, fatores antrópicos e a complexa interação entre esses fatores (REATTO et al., 2008, MIRANDA et al., 2004, RIBEIRO; WALTER, 2008, RIOS et al., 2018).

A localização central no Brasil faz com que o Cerrado esteja em contato com os Biomas Caatinga, Floresta Amazônica, Mata Atlântica, Pantanal, funcionando como um écotono, um corredor de passagem para animais mais generalistas que se deslocam para outros Biomas (RIBEIRO; WALTER, 2008, RIOS et al., 2018). Sua localização também colabora para a diversidade de espécies no Cerrado, que é estimada em cerca de 6.600 espécies vegetais sendo $40 \%$ endêmicas do Cerrado, tem a terceira maior fauna brasileira com cerca de 2.200 espécies animais (PRIMACK, 2002).

O segundo maior bioma da América do Sul, o Bioma Cerrado já ocupou cerca de $22 \%$ do território brasileiro, mas o cenário atual mostra que entre 50 e $80 \%$ do Cerrado já foi substituído por áreas agrícolas e menos de 4,5\% do Bioma está protegido em Unidades de Conservação (PRIMACK, 2002). Esse dado dá ao Cerrado o título de segundo Bioma mais ameaçado do Brasil e coloca em risco a diversidade biológica e os recursos hídricos presentes na área desse Bioma (RIOS et al., 2018). 


\section{Ponto: A vegetação do Bioma Cerrado e o Paredão da EGESA (barragem abandonada)}

Nesse local, foi possível visualizar espécies típicas do Cerrado de uso alimentar como por exemplo o cajuzinho, jatobá, baru, pequi, araticum, cagaita, mangaba e o abacaxi do cerrado. Foi um local estratégico para se falar da importância alimentar do Bioma (Figura 3A), relacionar com aspectos culturais da população local que utilizam esses frutos para alimentação.
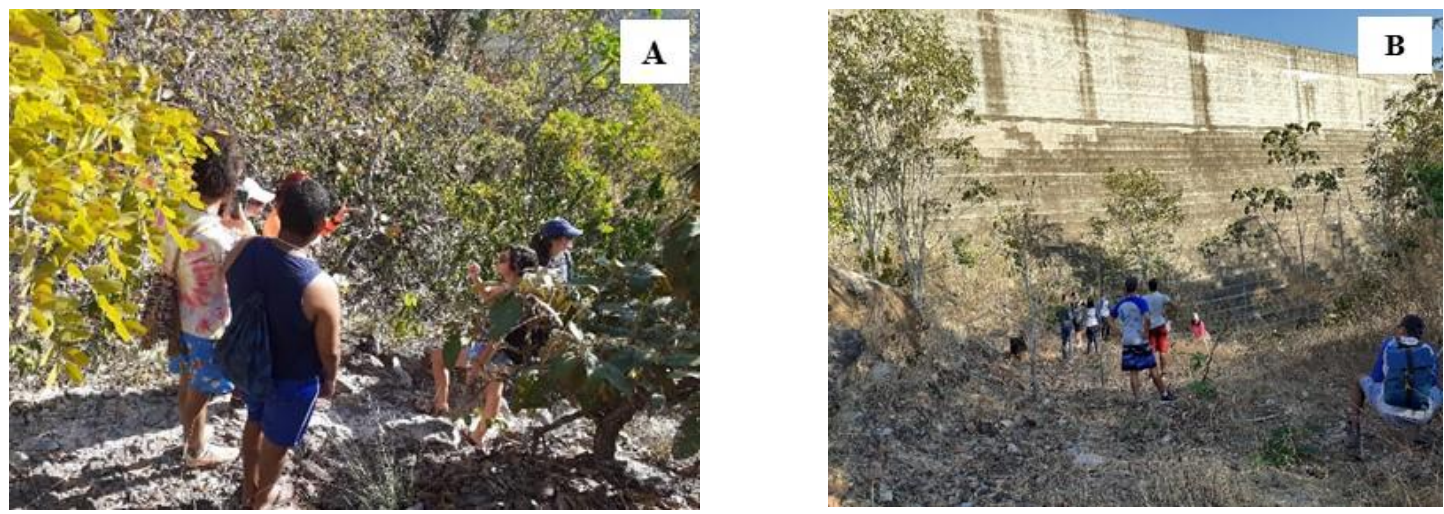

Figura 3: Pontos de interação para realizar interpretação ambiental: A - discussão sobre Cerrado e sua importância do alimentar e cultura local; B - discussão sobre o impacto da construção da barragem para o Cerrado e comunidade local.

Figure 3: Interaction points to perform environmental interpretation: A - discussion about the Cerrado and its importance of food and local culture; B - discussion on the impact of the construction of the dam on the Cerrado and the local community.

Fonte: Arquivo dos autores.

Source: Authors' archive.

Os participantes foram convidados a mostrarem o que conheciam do Bioma Cerrado destacando espécies conhecidas, uso, histórias e experiências pessoais com Cerrado. Esse ponto é bem próximo a construção de uma barragem (Figura 3B), hoje abandonada, os participantes puderam observar a dimensão da construção "inacabada" e discutiram o impacto da construção para o Cerrado e comunidade local.

\section{Ponto: A Cachoeira da antiga Usina}

$\mathrm{Na}$ Cachoeira (Figura 4A), os participantes tiveram um tempo para desfrutar do local com banho e lanche compartilhado. Em seguida foi retomada a discussão sobre a importância do Cerrado para manutenção dos recursos hídricos, os impactos deixados pela população que usa o local para recreação (Figura 4B), a relação histórica com a cidade por ser indicado como local onde se tinha uma pequena usina que levava energia para Arraias. Ao final do descanso, os participantes se voluntariaram para recolher (Figura 4C), das margens da cachoeira, lixo (garrafas, sacolinhas, embalagens de biscoito) deixado por outros visitantes. 

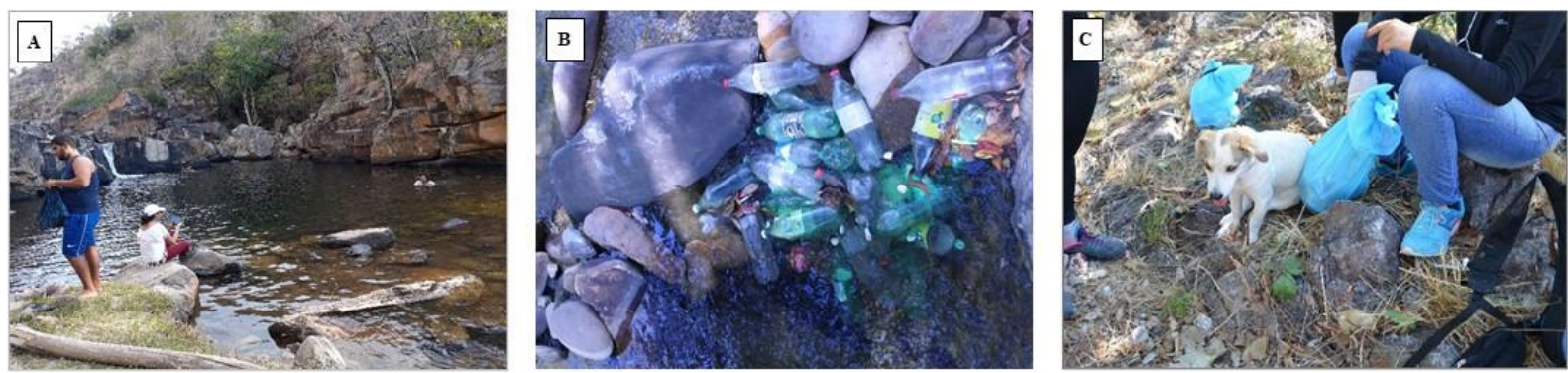

Figura 4: Cachoeira da Antiga Usina: A - momento para lazer; B - Discussões sobre impacto do lixo e importância do Cerrado para manutenção dos recursos hídricos; C - Participantes recolhem lixo das margens da cachoeira.

Figure 4: Waterfall of the Old Plant: A - leisure time; B - Discussions on the impact of garbage and the importance of the Cerrado for the maintenance of water resources; C - Participants collect garbage from the banks of the waterfall.

Fonte: Arquivo dos autores.

Source: Authors' archive.

O retorno ao LABECOTUR foi realizado por transporte da Universidade, o lixo recolhido foi depositado em lixeiras do Câmpus.

\section{Resultados}

Os resultados da pesquisa se referem as etapas referentes aos procedimentos metodológicos aplicados. Em um primeiro momento sobre o perfil e as respostas dos participantes sobre a prática do turismo e a acessibilidade para o público surdo, e em um segundo momento as respostas obtidas com a percepção dos participantes após a realização da trilha interpretativa com condução e intepretação em LIBRAS.

Quanto ao perfil dos participantes, 10 eram homens e 4 mulheres com idades entre 19 e 34 anos. Os participantes tinham origem em quatro cidades do estado do Tocantins: Tocantinópolis (1); Arraias (2); Palmas (5) e Porto Nacional (6). O grau de deficiência auditiva da maioria dos participantes foi classificado como profunda (9); média ou moderada (2); grave ou severa (1) e não souberam responder (2).

Dos 14 participantes, 12 afirmaram que gostam muito de viajar e relataram que ao viajar têm a possibilidade de conhecer novas culturas, cidades, ter contato com a natureza e conhecer outras comunidades surdas. Sobre a frequência que viajam, a maioria disse que viajam mais de 3 vezes por ano (7), seguido por 3 vezes ao ano (1), 2 vezes ao ano (1), 1 vez ao ano (1), menos de uma vez ao ano (1) e não souberam responder (2).

Ao serem questionados para elencar os principais motivos para viajar, a maioria respondeu para encontrar outros membros da comunidade surda seguido de visitar familiares, ir a congressos, lazer e turismo, respectivamente. Encontrar a comunidade também foi a principal motivação identificada em pesquisa realizada por Lopes (2017). $\mathrm{O}$ autor ressalta que a comunidade surda tem sua própria cultura e isso faz com os surdos se sintam mais confiantes e mais seguros por estarem juntos e terem melhor comunicação ao realizarem deslocamentos e viagens de turismo.

A maior parte dos participantes indicaram que preferem viajar com amigos surdos. Para Silva (2013) a maior dificuldade para que o surdo viaje sozinho está na comunicação. Saber a escrita e a leitura da língua portuguesa faz diferença, já que a comunicação em LIBRAS, geralmente fica restrita à grupos de pessoas surdas. Esse 
também é um dos motivos que levam muitas vezes a viajar com os amigos ouvintes, porque são pessoas que os entendem e que facilitam a comunicação com outros públicos.

Silva (2013) afirma que a barreira principal para a pessoa surda em relação ao turismo é a falta de comunicação. Para o autor, não há no turismo um atendimento de qualidade para as pessoas surdas de forma geral, e embora os participantes tenham indicado que gostam de viajar, a visita a lugares turísticos ainda é limitada devido a ausência de profissionais capacitados e sinalização correta.

As respostas registraram que sete participantes indicaram já terem tido problemas durante viagens, com destaque para a dificuldade de comunicação em atrativos turísticos. Os participantes indicaram o acesso a serviços em lojas, setor rodoviário, e de atendimento ao turista como os principais problemas em viagens, como nestes exemplos relatados a seguir:

Participante 1: relata que em uma atividade guiada, não tinha profissional com formação em LIBRAS, e que se sentiu desvalorizado e que não foi bem recepcionado como um turista pelo fato de ser uma pessoa surda.

Participante 3: apontou por exemplo a dificuldade que teve para se comunicar com motoristas, tendo que buscar alternativas como gestos, desenhos, escrita para fazer o motorista entender o que queria.

Participante 6: indicou que no guichê da empresa de ônibus não havia profissional para atendê-lo e que não queriam Ihe dar o "passe livre" de direito da pessoa surda. pois além de ter problema de comunicação o funcionário não conhecia o direito da pessoa surda.

A falta de Intérpretes de LIBRAS foi a dificuldade destacada por sete dos participantes em relação ao turismo. Diante das respostas percebe-se que a comunidade surda ainda possui muitas barreiras a serem quebradas. As dificuldades encontradas pela pessoa surda acabam interferindo em suas escolhas. Essa situação pode levar a pessoa surda a optar por companhia de ouvintes em viagens, a fim de reduzir os problemas de comunicação ou não visitarem alguns atrativos turísticos, principalmente àqueles onde há a necessidade de guiamento ou monitoria.

A acessibilidade, segundo 10 dos participantes da pesquisa é muito importante na hora da escolha do destino turístico. Eles atribuem essa importância principalmente à presença de tradutor/intérprete para promover a comunicação na atividade turística, facilitar a interação entre surdos e ouvintes e acessar o conhecimento sobre os atrativos visitados. Relatam que a comunidade surda sente a necessidade de conhecer novos lugares, aprender sobre a cultural local e o patrimônio, mas não conseguem ter esse atendimento na maioria dos lugares turísticos que frequentam.

A dificuldade de comunicação e a importância da acessibilidade, registradas nesta pesquisa, também foram observadas por Lopes (2017). Esse autor explica que a acessibilidade é importante e influência na avaliação e escolha do atrativo pelo turista surdo.

Para Lopes (2017, p. 47-48), “a falha ou falta na comunicação se constitui como um obstáculo a ser vencido pelo surdo e um fator a ser melhorado pelos atrativos 
turísticos e prestadores de serviços públicos ou privados", visto que a falta de pessoas capacitadas para realizar atendimentos específicos como em hotéis ou balcões de informações poderá acarretar uma experiência negativa ao turista surdo

Sobre a trilha interpretativa oferecida aos participantes obtivemos resultados satisfatórios num contexto mais geral, pois em primeiro lugar cabe destacar que foi a primeira vez que todos os participantes fizeram uma trilha de ecoturismo interpretativa com condução e a mediação de intérpretes de LIBRAS.

Após o retorno da atividade, a qual foi denominada "Ecoturismo e Acessibilidade, uma trilha em LIBRAS", foi registrada a opinião de cada um deles sobre a atividade em si e sobre a experiência de participação em uma trilha interpretativa a partir da aplicação do questionário com perguntas abertas.

De acordo com alguns relatos, percebemos que a experiência e a acessibilidade somente por haver um intérprete de LIBRAS na trilha fez uma grande diferença na experiência turística do público, bem como dinâmica de uma trilha interpretativa de ecoturismo os proporcionou novos conhecimentos, como seguem nos seguintes relatos dos participantes:

Participante 1: É importante estimular os guias a terem a oportunidade de aprender os sinais de nível básico em LIBRAS para facilitar a acessibilidade para a pessoa surda.

Participante 3: Foi a primeira vez que participei de uma trilha, gostei muito.

Participante 4: Foi muito bom poder receber conhecimento sobre os tipos de árvores e frutos que o cerrado possui, sobre como a população da cidade usa as plantas.

Participante 5: O surdo gosta de conhecer, de saber sobre as coisas, pessoas lugares. Precisa ter mais atividade para surdos.

Participante 8: foi muito bom. Iniciativa de ofertar a trilha foi muito boa, deve continuar. Participar de atividade de conhecer cerrado, beleza da cachoeira, participar da coleta de lixo no caminho, discutir questões ambientais é muito importante para todos e para o surdo não é diferente.

As respostas evidenciaram a necessidade de promover a acessibilidade e a inclusão da pessoa surda em todos os aspectos. Elas demonstram muito interesse e o desejo de frequentar determinados espaços e consumir certos serviços como os serviços turísticos, mas para isso é necessário abrir espaços e atividades que possibilitem a valorização e atendimento ao público surdo.

Sobre o percurso da caminhada, cerca de 2,5 km pelo Cerrado de Arraias, os participantes fizeram muitas paradas para observar e tocar os elementos que se apresentavam no percurso, tudo isso mediado por uma bióloga (condutora) e um intérprete de LIBRAS. À medida que algo chamava a atenção, os participantes utilizavam o tato, o cheiro e até o paladar para interagir com esses elementos.

O grupo demonstrou muito interesse em tocar as plantas, pedras e sementes encontradas, e em provar frutos, como o cajuzinho do cerrado e o baru. No percurso, os participantes também estavam animados e buscavam comunicar suas experiências e pensamentos com os demais participantes e com os organizadores. Alguns 
mostraram ter conhecimento sobre o Cerrado e compartilharam com todos; outros expressaram sua alegria pela oportunidade de realizar a atividade.

Uma das atividades proposta para a trilha foi a "dinâmica do anjo" (Figura 5), a atividade funcionou além do esperado e foi possível observar que o grupo foi muito atencioso e colaborativo. Compartilhar os momentos e o que percebiam foi uma constante na atividade.

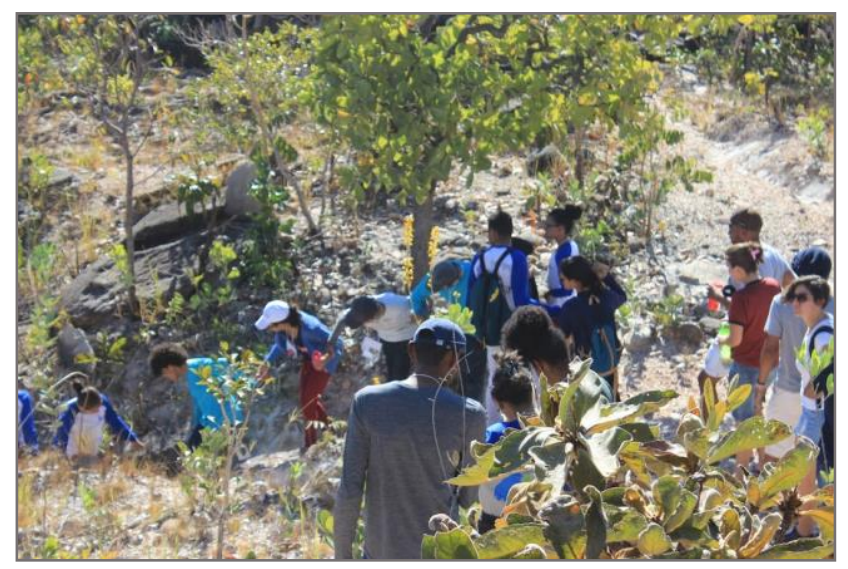

Figura 5: Dinâmica do anjo em prática. Figure 5: Angel dynamics in practice. Fonte: Arquivo dos autores, 2019.

Source: Authors' archive, 2019.

Durante a trilha observou-se que o participante surdo demanda de um tempo e atenção diferente do ouvinte. O tempo calculado para desenvolvimento das atividades com a pessoa surda não foi adequado o que mostra a necessidade de mais pesquisas e organização de atividades para esse público específico. Para uma trilha com pessoas surdas é preciso tempo para estabelecer contato visual com os participantes e o intérprete, no sentido de traduzir as informações para a LIBRAS.

Antes de adentrar no transporte para retorno, os participantes tomaram a iniciativa de agradecer pela atividade, relatando o contentamento com a experiência vivenciada, parabenizando e recomendando a continuidade de propostas voltadas para atendimento à pessoa surda em atividades de lazer e turismo.

\section{Considerações finais}

O lazer e o turismo como produtos da indústria cultural têm se inserido na sociedade como possibilidade de desenvolvimento socioeconômico e ao mesmo tempo de distinção social, pois sabe-se que como qualquer produto eles não estão disponíveis ao consumo de todos, em especial, aos mais pobres e às minorias, como às pessoas com deficiência ou com necessidades específicas, que mesmo com disponibilidade financeira, não são incluídas nestas atividades por falta de estrutura, profissionais capacitados e políticas públicas efetivas.

A proposta aqui discutida e apresentada versou sobre o planejamento e a oferta de uma trilha interpretativa de ecoturismo para um grupo de pessoas surdas, bem como apresentou as impressões deste grupo sobre a participação em uma trilha interpretativa e a acessibilidade ao público surdo no ecoturismo. 
Nestes termos, observou-se que, em um contexto geral são poucos os estudos sobre a temática do turismo e a acessibilidade, bem como turismo e a pessoa surda. Sendo assim, considera-se que este tema deve ser mais bem estudado e voltado às necessidades de inclusão social deste público na sociedade, e principalmente inseridos nas atividades de lazer e do turismo como direitos de qualquer cidadão.

As trilhas interpretativas têm na sua organização o objetivo de agregar conhecimento sobre a natureza a partir de uma linguagem acessível ao visitante, de certa forma o que a trilha interpretativa proporciona, pode ser entendida como sendo "traduzir a linguagem da natureza" (BLENGINI et. al, 2019). Nesse sentido, uma trilha interpretativa deve incluir a LIBRAS como uma das linguagens de acesso à informação e interação com natureza, como forma de possibilitar reflexão discussões sobre questões ambientais e de lazer.

A trilha interpretativa foi ofertada em formato piloto e elaborada pelo Laboratório de Ecoturismo da UFT Campus de Arraias dentro de um projeto de pesquisa do curso de Turismo Patrimonial e Socioambiental. Como forma de aprendizado a experiência foi satisfatória para os acadêmicos e docentes participantes, pois foi possível aprender e observar as potencialidades e problemas do ecoturismo a partir da questão da acessibilidade.

Os resultados mostraram que a inclusão social dentro da atividade turística em geral e especificamente no ecoturismo ainda necessita de melhorias quanto a estrutura física, profissional e ao que se refere a comunicação com o público surdo. Neste contexto, identificou-se a importância da Língua Brasileira de Sinais- LIBRAS na atividade turística para que a pessoa surda possa obter acesso de qualidade às diferentes áreas do lazer e do turismo.

Foi evidenciado que a presença de um intérprete em LIBRAS já seria suficiente para atender ao interesse da pessoa surda e que a acessibilidade física da trilha não se mostrou um empecilho na medida em que os participantes se sentiram animados e capazes em relação a atividade proposta. A realização de uma trilha interpretativa com condutores e direcionada para surdos também foi destacado como diferencial e cuidado com esse público, e neste caso, o uso da LIBRAS para condução da atividade proposta na trilha interpretativa de ecoturismo demonstrou as diversas possibilidades de inclusão social por meio das atividades turísticas.

Do ponto de vista dos participantes da trilha e dos resultados da pesquisa após avaliação, conclui-se que a experiência turística e inclusão social do público surdo foi estimulante e satisfatória, pois como relatado não há para esse público em geral, atividades de lazer e turismo adaptadas. Demonstrou também a necessidade de conhecimentos em LIBRAS, o que leva a reflexão da importância da oferta de disciplinas de LIBRAS nos cursos superiores, em especial nos cursos de turismo.

\section{Referências}

ANDRADE, L. L. de: ALVES, A. M. A inclusão do surdo na atividade do turismo através do uso de libras. 2011, f. 16, Monografia (Bacharelado em Turismo) - Fundação Visconde de Cairu, 2011.

BLENGINI, I. A. D., et. al. Trilha interpretativa como proposta de Educação Ambiental: um estudo na RPPN do Caju (SE). Revista Brasileira de Ecoturismo, São Paulo, v.12, n.1, fev/abr 2019, p. 142-161. 
BRASIL. Decreto n 3.298 e 20 de dezembro de 1999. Regulamenta a Lei no 7.853, de 24 de outubro de 1989, dispõe sobre a Política Nacional para a Integração da Pessoa Portadora de Deficiência, consolida as normas de proteção, e dá outras providências. <http://www.planalto.gov.br/ccivil 03/decreto/d3298.htm>. Acesso em: 07 out. 2019.

BRASIL. LEI № 13.146, DE 6 DE JULHO DE 2015. Institui a Lei Brasileira de Inclusão da Pessoa com Deficiência (Estatuto da Pessoa com Deficiência). Disponível em: <http://www.planalto.gov.br/ccivil 03/ ato20152018/2015/lei/l13146.htm>. Acesso em: 20/07/2020.

BRASIL. Código de Ética Mundial do Turismo. Ministério do Turismo. Disponível em:

$<$ http://www.turismo.gov.br/sites/default/turismo/o ministerio/publicacoes/downloads publicacoes/PREVIEW MTUR Codigo de Etica Turismo $120210 \mathrm{~mm}$ Portugues .pdf>. Acesso em: 08 out. 2019.

BRASIL. Instituto Brasileiro de Geografia e Estatística - IBGE. Estatísticas. Disponível em: https://cidades.ibge.gov.br/brasil/to/arraias/panorama Acesso em 18 maio 2010.

COSTA, L. de A. da. Turismo Adaptado: Acessibilidade turística para cadeirantes nos cincos principais atrativos turísticos da cidade de Curitiba-PR. 2012, f. 97, Monografia (Bacharelado em Turismo) - Universidade Estadual do Centro - Oeste - UNICENTRO, Campus de Irati, 2012.

DUMAZEDIER, J. Sociologia empírica do lazer. São Paulo, Perspectiva SESC, 1999.

EISENLOHR, P. V. et al. Trilha e seu papel ecológico: o que temos aprendido e quais as perspectivas para a restauração de ecossistemas? Hoehnea 40(3), 2013, p. 407 418.

FLORÊNCIO, I. C. de M. Protótipo de um aplicativo turístico da cidade de Caruaru para a comunidade surda. 2016, f. 62. Monografia (Curso de Design) - Universidade Federal Universidade Federal de Pernambuco, 2016.

IRVING, M. Turismo, áreas protegidas e inclusão social: Uma triangulação necessária em planejamento, no caso brasileiro. In: IRVING, M.A.; R., CAMILA, G.O.; RABINOVICI, A. (Orgs.). Turismo, áreas protegidas e inclusão social: diálogos entre saberes e fazeres. Rio de Janeiro. Folio Digital: Letra e Imagem, 2015.

LAGES, S. R. C.; MARTINS, R. Turismo inclusivo: a importância da capacitação do profissional de turismo para o atendimento auditivo. Estação cientifica, Juiz de Fora, n.03, out. 2006, p. 1-17.

LIMA, R. P. Turismo sem barreiras: uma proposta para aumentar a inclusão dos deficientes nas atividades turísticas. 2004, f. 67, Monografia (Especialização em Gestão e Marketing do Turismo) - Universidade de Brasília-UnB, Brasília-DF, 2004.

LIMA, M. M. P.; SILVA, L. da. Educação Ambiental Através de Trilha Interpretativa em Área Protegida no Município de Quixadá-CE. CONIDIS I Congresso Internacional da Diversidade do Seminário. Disponível em: <https://editorarealize.com.br/revistas/conidis/trabalhos/TRABALHO EV064 MD1 S A7 ID898 30082016114101.pdf>. Acesso em: 23 mar. 2020. 
LOPES, K. H. C. TURISMO: o surdo e a viagem. 2017, f. 77, Monografia (Centro de Excelência em Turismo) - Universidade de Brasília-UnB, Brasília-DF, 2017.

LUCHIARI, M.T.D. P. O lugar no mundo contemporâneo: Turismo e urbanização em Ubatuba - SP. Tese (doutorado), 277 pp. Universidade Estadual de Campinas, Instituto de Filosofia e Ciências Humanas, 1999.

MENDES, B. C.; PAULA, N. M. de. A hospitalidade, o turismo e a inclusão social para cadeirantes. Turismo em Análise, V. 9, n. 2, ago. 2008, p. 329-343.

MIRANDA, H. S. et al. Queimadas de Cerrado: caracterização e impactos. In: AGUIAR, L. M. D. S.; CAMARGO, A. J. A. (Ed.). Cerrado: ecologia e caracterização. Planaltina: EMBRAPA Cerrados, 2004, p. 69-123.

OLIVEIRA, F. V. de. Patrimônio cultural e natural, turismo e desenvolvimento local no município de São José do Barreiro - SP: Uma esperança condicional. 2020. 228 f. Tese (Doutorado em Ciência Ambiental) - Instituto de Energia e Ambiente. Universidade de São Paulo, São Paulo, 2020.

PRIMACK, R. B; RODRIGUES, E. Biologia da Conservação. Londrina: Editora Planta. 2002.

PRODANOV, C. C.; FREITAS, E. C. de. Metodologia do trabalho científico: métodos e técnicas da pesquisa e do trabalho acadêmico. E-book. 2. ed., Novo Hamburgo: Feevale, 2013.

REATTO, A. et al. Solos do Bioma Cerrado: aspectos pedológicos. In: SANO, S. M.; ALMEIDA, S. P.; RIBEIRO, J. F. (Orgs). Cerrado: ecologia e flora. Planaltina: Embrapa; CPAC, 2008, p. 107-150.

RIBEIRO, J. F; WALTER, B. M. T. As principais fitofisionomias do Bioma Cerrado. In.: SANO, S. M; ALMEIDA, S. P; RIBEIRO, J. F. (Orgs.). Ecologia e flora. Brasília: EMBRAPA, 2008, p. 151-212.

RIOS, M. N. S. et al. Mudanças pós-fogo na florística e estrutura da vegetação arbóreo-arbustiva de um cerrado sentido restrito em Planaltina, DF. Ciência Florestal, Santa Maria, v. 28, n. 2, 2018, p. 469-482.

SANTOS, S. FREITAS dos; AMARAL, A. F.; MESSIAS, N. C. Rio Arraias: potencialidades turísticas na região das Serras Gerais. In: BALSAN, R.; NASCIMENTO, N. N. do; OLIVEIRA, M. C. A. de (Orgs.) Identidades do turismo no tocantins. Palmas: EDUFT. 2020, p. 76-85.

SANTOS, M. C. dos; FLORES, M. D.; ZANIN, E. Maria. Trilhas Interpretativas como instrumento de interpretação, sensibilização ambiental na APAE de ERECHIM/RS. Revista Eletrônica de Extensão da URI. vol. 7, n. 13, 2011, p. 1-9.

SILVA, M. ACESSIBILIDADE EM TURISMO: a acessibilidade dos surdos aos serviços turísticos de Goiânia-GO, Turismo em Análise, v. 24, n. 2, ago. 2013, p. 1-20.

SHIMOSAKI, R. Roteiro Inclusivo Para Surdo. Turismo Adaptado. 30 mai. 2019, p. 1. Disponível Disponível em: <https://turismoadaptado.com.br/roteiro-turisticoinclusivo-para-surdos/>. Acesso em: 06 nov. 2019. 


\section{Notas:}

Agradecimento especial: Aos participantes da pesquisa, ao professor Vinícius Pedroni e a servidora Raquel Nascimento.

A autoria deste artigo segue ordem alfabética dos nomes dos autores.

Alice Fátima Amaral: Universidade Federal do Tocantins, Arraias,TO, Brasil.

E-mail: alicefamaral@uft.edu.br

Link para o currículo Lattes: http://lattes.cnpq.br/2992153615005024

Filipe Vieira de Oliveira: Universidade Federal do Tocantins, Arraias,TO, Brasil.

E-mail: filipeoliveira@mail.uft.edu.br

Link para o currículo Lattes: http://lattes.cnpq.br/4021801620291868

Thamyris Alves de Sousa: Universidade Federal do Tocantins, Arraias,TO, Brasil.

E-mail: thamyresa50@gmail.com

Link para o currículo Lattes: http://lattes.cnpq.br/8195525441083960

Data de submissão: 05 de julho de 2021

Data de recebimento de correções: 08 de setembro de 2021

Data do aceite: 08 de setembro de 2021

Avaliado anonimamente 